\title{
Work attitude of Ghanaian nurses for quality health care service delivery: Application of Individual and Organizational Centered (IOC) interventions
}

Asamani, Lebbaeus

University of Cape Coast, Ghana (lebbaeus.asamani@ucc.edu.gh)

Agyemang, Badu Collins

University of Professional Studies, ACCRA, Ghana (collins.agyemang@upsamail.edu.gh)

Afful, Joana

Airforce Medical Services, Takoradi, Ghana (joanafful@yahoo.com)

Asumeng, Maxwell

University of Ghana, Legon, Ghana (masumeng@ug.edu.gh)

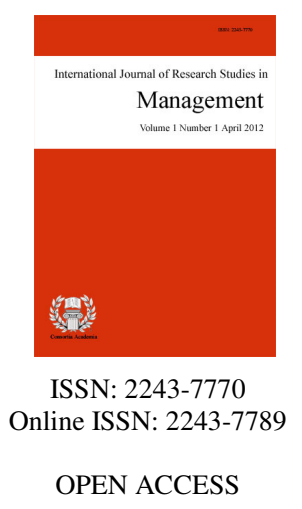

OPEN ACCESS

\section{Abstract}

Among all the health professions in Ghana, it is arguable but lucid that nurses have by far the most patient or clientele contact. It is banal that nurses are the most lambasted in respect of their treatment of patients or clients in Ghana. The present paper elaborates on these sentiments as exemplified across Ghana and attempts to provide answers to why the nurses hold unfavorable attitude toward the patients as well as how they form the generally unhealthy attitude at their work-settings. Underpinned by the concept of emotionology (with reference to local cultural patterns and nurses level of experience/exposure to patients' pain) and high patient-nurse ratio, nurses' odious attitude from Ghanaian patients' perspective, is expounded. The authors thus provide an Individual and Organizational-Centered (IOC) intervention strategy from organizational development perspective as a viable and effective route to negate patients' sentiments while addressing Ghanaian nurses' attitude toward quality health-care delivery.

Keywords: nurses attitude; quality health-care delivery; patient-nurse ratio; Individual and Organizational Centered (IOC) interventions 


\section{Work attitude of Ghanaian nurses for quality health care service delivery: Application of Individual and Organizational Centered (IOC) interventions}

\section{Introduction}

The demand for quality health-care delivery is a necessity in every nation, and quality health care is a right of the people which must not be traded for anything. The quality of health care delivery depends largely on the attitude of the health workers. Nursing care is one of the major health care services that contribute significantly to the patient's healing process. Even though there may be competent physicians present in a given health institution, it would be inadequate without appropriate nursing care. A national conference in Ghana which sought to address the "eroding compassion" of nurses and midwives was held in December, 2013. This was necessitated by the increasing public outcry against poor attitudes of nurses toward clients and patients at health facilities (Appiah, 2013). A number of studies, media reports and personal experiences of the writers, indicate that, generally, the attitude of nurses in Ghana is unhealthy, which is hampering health delivery in the county.

All over the world, there is a paradigm shift toward client-centered health-care delivery. But the situation is different in Ghanaian hospitals, especially the public hospitals. It is not uncommon to hear nurses shout and humiliate patients who seek explanation to certain things concerning their health. In order to avoid these humiliations, patients simply keep quiet and do whatever they are asked to do without question. A patient may return from hospital and when relatives or friend ask, "What was the diagnosis of your health condition?", the response would be, "I don't know. The doctor only prescribed these drugs for me to buy without any explanation." The impression here is that, the health workers claim to be omniscient. This attitude, especially, that of the nurses who are the "customer relations officers" of the health institutions, is helping to promote quality health-care delivery in the country. Many people prefer to stay at home and do self-medication than to go to the hospital and be humiliated by nurses, while others turn to the traditional or native doctors for help.

Indeed, Asenso-Okyere, Osei-Akoto, Anum, and Adukunu (1999) noted that the attitude of health workers is one of the major factors considered by patients when choosing a health care provider. These authors noted that many patients have resorted to traditional health care because both the herbalist and the fetish priest devote a lot of time to the patient, adding a personal touch to the treatment. Well-resourced individuals go to the private hospitals that tend to treat patients with some level of respect because of their profit maximization orientation.

A featured article by Ghana News Agency in June 22, 2012, indicated that the Nurses and Midwives Council (NMC) expressed concern about poor client-centered care by some of its members occurring in most of the nations' health care institutions. This prevents a number of people from going to the hospital when they are sick. Apem-Darko (cited in Ghana News Agency, June 22, 2012), lamented that the professional virtues of empathy, love, affection and innovation among nurses (as exhibited by Florence Nightingale) were diminishing and that there was the need for nursing trainees to imbibe these treasured values to render professional services to their cherished patients, clients and family. Patients (clients) go to the hospital when they are sick and so might not be in the right frame of mind. This makes it imperative that they get the necessary information from them to provide client-centered service with empathy (GNA, June 22, 2012).

Asare-Allotey (as cited in Salia, 2007) also reported in an article entitled, "Nurses' attitude deplored", admonished that nurses must not hide behind the constraints facing them at the health centres to perpetuate discourteous acts towards their clients. According to the paper, a self-appraisal report by the association indicated that the "public had no problem with the skills of nurses but rather the way they communicated and received patients." The attitude of some nurses and midwives had become a major challenge in the healthcare delivery service and also sunk the image of the profession (Dzomeku, Ba-Etilayoo, Perekuu, \& Mantey, 2013). 
Work attitude of Ghanaian nurses for quality health care service delivery: Application of IOC interventions

Asare-Allotey also observed the way nurses received their patients had about 60 per cent healing on them and implored all nurses to join hands with the GRNA to deal with the negative attitudes of some of the nurses. Appiah (2013) also reported in graphic online that that the Chief Nurse and Midwifery Officer warned that "nurses and midwives who display poor attitude towards patients would be sanctioned by health authorities." These sanctions would include suspension for poor work attitude and withdrawal of licences with serious breach of the code of ethics of the profession.

The Assemblyman of Akwapim North District of Ghana noted that the nurses and midwives in the area had bad human relations and were not able to relate well with patients and their relatives. He consequently, called for the transfer or replacement of nurses with those who could relate well with patients (Shirimori/Ghanadistrict.com, 2001).

Lastly, a man narrated his ordeal in one of the major government hospitals in Accra with pain when they lost their child through some of these unacceptable attitudes of nurses. According to the man, the wife was in labour on one bed which seemed to be too small for her. It was decided that the bed should be changed. The nurse on duty forced the woman in labour to get down and walk to the other bed (which could have been move to where the other one was for smooth change). Note that, at this point, the head of the baby had already come out and sagging between her legs. Just as she complied and started walking, the baby fell and died instantly (Personal communication, $8^{\text {th }}$ February, 2014).

\subsection{Statement of the problem}

Though there have been various concerns about the attitude and behaviour of nurses and the need for change of attitude, most studies only investigated the prevalence of the unhealthy attitude and whether the attitude has changed over time (Asenso-Okyere et al., 1999). There has not been any systematic and pragmatic intervention to deal with the situation in Ghana. The code of ethics for the Ghana Health services provided for client-centred health care in the country, but the converse is what is happening now. Various authorities threatened to sanction nurses who exhibit unprofessional attitude, but the situation is worsening day after day. The question then is: "can these unhealthy attitudes that are clearly unwelcoming within the Ghanaian society in the health-care system be altered?"

This paper reviewed and analyzed pertinent literature regarding the nature of the work attitude of the nurses from both the nurses' and patients' perspective. Explanations are provided as to why the nurses exhibit unfavorable attitude toward the patients. A critical review of best practices and intervention strategies from organizational development perspective were proffered to help improve upon the quality of the nurse-patient relationship. The model offered in this paper is referred to as the Individual and Organisational Centred (IOC) model. This model recognises that the attitude and behaviour of the workforce is influenced by both individual and organisational variables, and a comprehensive management would mean that the issue must be tackled from both contexts.

\section{Theoretical Framework}

Baron, Branscombe, and Byrne (2009) define attitudes as relatively lasting clusters of feelings, beliefs, and behaviour tendencies directed towards specific persons, ideas, objects or groups. Attitudes explain an individual's behavior and they encapsulate a complex combination of a myriad of variables such as personality, beliefs, values, behaviors, and motivations. Pickens indicated that attitude encapsulates a person's emotions and behaviors. For instance, nurses' attitude toward patients encapsulates how they perceive and think about the patients (thought); how they feel about them (emotion), and the actions (behaviors) they exhibit toward them. This is the tri-component (ABC) model of attitudes which holds that an attitude includes three components: an Affect (a feeling), Cognition (a thought or belief), and Behavior (an action). Attitudes help us define how we see situations, as well as define how we behave toward the situation or object. 
The question of how attitudes are formed and changed has been an issue in Social Psychology since the construct was introduced by Thomas and Znaniecki in 1918, and expanded by Gordon Allport in 1935 (Betsch, Plessner, \& Schallies, 2004). Green (as cited in Jones, n.d.) states that any attitude is a hypothetical or latent variable rather than an immediately observable variable. He observed further that the concept of attitude does not refer to any one specific act or response of an individual, but it is an abstraction from a large number of related behavior or responses. For instance, the view that nurses have unfavorable attitude towards their patients encapsulates a generalization of their behavior or actions toward their patients in different contexts.

Attitude formation was largely seen to follow general learning processes such as classical and operant conditioning after the Second World War, which suggests that attitudes are largely shaped by the context (Betsch, Plessner, \& Schallies, 2004). According to this view, the actor plays a rather passive role and attitudes unwittingly emerge as a by-product of learning and socialization. Beginning with the new look movement (e.g., Bruner, cited in Betsch, Plessner, \& Schallies, 2004) attitude researchers became more concerned with cognitive processes. This led to viewing attitude formation and change as an active, cognitive process which involves understanding and elaboration of persuasive information (McGuire, 1968). At the same time, formal models from other disciplines, mainly statistics and probabilistic decision theory, were imported into psychology and employed to describe mental operations (Edwards, 1954).

In the early 1960s, rational concepts of the human mind were proposed and judgments and decisions were assumed to primarily reflect thinking and reasoning rather than automatic operations. The theory of reasoned action (Fishbein \& Ajzen, 1975) represents the most prominent example of this line of theorizing. According to the theory of reasoned action, attitudes are the product of explicit deliberation (Ajzen \& Fishbein, 1980, p. 5) involving the anticipation and weighted integration of valued consequences associated with an attitude object. Attitudes are held with respect to some aspect of the individual's world, such as another person, a physical object, behaviour, or a policy (Ajzen \& Fishbein, 1980). That is to say that the attitude depicted by the nurse toward their patients might have been engendered by certain aspects of their work environment. These may include certain aspects of the behaviour of the patients, infrastructure, resources availability and allocation, work policies, and many others. Thus, the way they respond to various aspects of their work context or environment constitutes their attitude at work.

\section{Explanations for Nurses' Attitude}

Patients in Ghana have often complained about the behaviour of some health workers, especially, nurses which have tended to aggravate their illness. In general, patients did not speak well of nurses. As observed by Asenso-Okyere et al. (1999), the general opinion was that nurses did not treat patients well and in some cases were rude to them. Some people are of the view that present day nurses do not care whether you are paying for the treatment or not, and that they do not work for the love of the vocation any longer.

Ghana health Service report in 2011 indicates that there is a huge deficit of nurses in the urban centres of Ghana and is most severe in small towns and rural areas (Ghana Health Service, 2011). Nurses are in short supply throughout the country resulting in high demand. Great need exists for nurses at all levels of operations: be it in care settings at hospitals, outpatient centres, community clinics, psychiatric centres and schools. This is not surprising as the nursing deficit is also mirrored in a shortage of nursing training centres or schools as well as their teachers in Ghana. Booth (2002) stated that fewer people are choosing the nursing profession and the current nurses are aging.

From Ghanaian patients' perspective, the few people who enter the nursing profession do so only for the sake of employment and not with the same mind set as did Florence Nightingale years ago. With high unemployment in Ghana, many are forced to choose career wisely. The idea that job search is a job in itself directs many young ones to choose nursing or teaching as they are sure of placement soon after their training. It looks apparent that many nurses may be working as such not for need of care for patients but for want of 
Work attitude of Ghanaian nurses for quality health care service delivery: Application of IOC interventions

employment. If this is so, patient-nurse relationship is likely to suffer.

Nurse-patient ratio in Ghana is another factor to consider in unravelling the possible causes of nurses indifferent attitude to patients. In Ghana, there is a high deficit of nurses across the country. In a 2012 Ghana Health Service report of the Asunafo District of the Brong Ahafo Region for instance, the nurse-patient ratio is reported to be $1: 6,705$. It is intriguing to say that the District has only one Medical doctor as at this report serving about 93,859. It is apparent that with Doctor-patient ratio of 1:93,859, many of patients' cases will be attended to by the few nurses.

The situation is much worrying upon considering the national figures. Commenting on the population to nurse ratio in Ghana, the 2011 Ghana Health Service report in the executive summary reads
"Trends over the three- year period under review (2009 - 2011), the population- to- nurse ratio decreased to 1,240 clients: Inurse, in comparison to 1,489:1 (2010) and 1,497:1(2009). Similarly, the population-to-doctor ratio has improved from 10,483:1 (2010) to 10,032:1(2011). This is encouraging for the Health Service, particularly at a time when it is positioning itselffor universal coverage” (p. 3).

While these figures look encouraging from past records according to the report, to what extent does patient-nurse ratio of about 1:1,300 (on the average) nationwide, be deemed encouraging? Can the wide margin of intended work load of nurse-patient contact affect their role as effective care givers and for that matter their attitude to patients?

In a statement by Dr Sodzi- Tettey (GNA, Monday, 7 July 2008), nurses may choose to work in private health centres (as locum staff) as a second job because of these shortages and in an attempt to top-up their meagre salary (between GHC 1, 200- GHC 1,600). This implies back-to-back shifts as they alternate between the regular job and the locum. While the hard work of these nurses may pay-off in their pockets, the rippling effect is impatience and indifferent attitude as they may have been exhausted already.

According to Asensu-Okyere et al. (1999) in reacting to the criticisms levelled against them, some nurses claimed that the type of behavior they put up sometimes was in reaction to the rudeness of patients, especially when it came to paying for treatment. Some nurses complained that at times, hospital patients did not have money to purchase drugs and the nurses on duty had to stand in for them at the dispensary only to discover that the patients had run away upon discharge without paying. The nurse who guaranteed the payment had to pay the money to the pharmacist or the dispensary attendant who did not know the patient. Such behavior resulted in huge debts to a number of nurses which had eroded their sympathies towards poor patients in critical health conditions. Other reasons proffered by the nurses is that, they are over-stressed and that is what sometimes engenders their poor human relations toward the patients. The stress, they claim, is due to inadequate infrastructure and nursing staff.

The concept of emotionology must be considered be considered in trying to explain the attitude of nurses. Emotionology, according to Stearns and Stearns (1988) refers to the attitudes or standards that a definable group within the society, maintains toward basic emotions and their appropriate expression". By inference, nurses' attitude toward the basic emotions of patients in varying intensity and perhaps in a crescendo manner makes them express themselves in the way they do. While on-looking patients may blame nurses blatantly, there is the need to consider the extent to which they respond appropriately to the various groaning and sighing of patients' most of whom might be in pain.

From another outlook, gleaning from Zborowski's (2010) paper entitled 'Cultural Components in Responses to Pain'; cultural patterns play a vital role on one's attitudes toward and reactions to pain. While Zborowki (2010) argues only on the lines of cultural patterns, we would want to add that a nurses level of experience and exposure to pain as another factor that affect their attitude toward and reaction to a patient's pain. For instance, from the 
Ghanaian phraseology, "a real man does not cry". A crying man receiving treatment from a nurse is likely to be treated with indifference as per this cultural definition of a man, which lends support to Zborowki (2010)'s argument. From the authors viewpoint, a nurse with much worth of experience may weigh a patient's present level of pain, complains, groaning, shouting, and compare in his/her minds-eye with some past memories of severe cases than the present. This may affect their attitude and reaction to pain and for that matter the demands of the patient. Some nurses may have to prioritise who to attend to base on their experience of real pain while others unattended to may equate their priority as a negative attitude to them. Figure 1 shows some identified factors that affect nurses' attitude in Ghana.

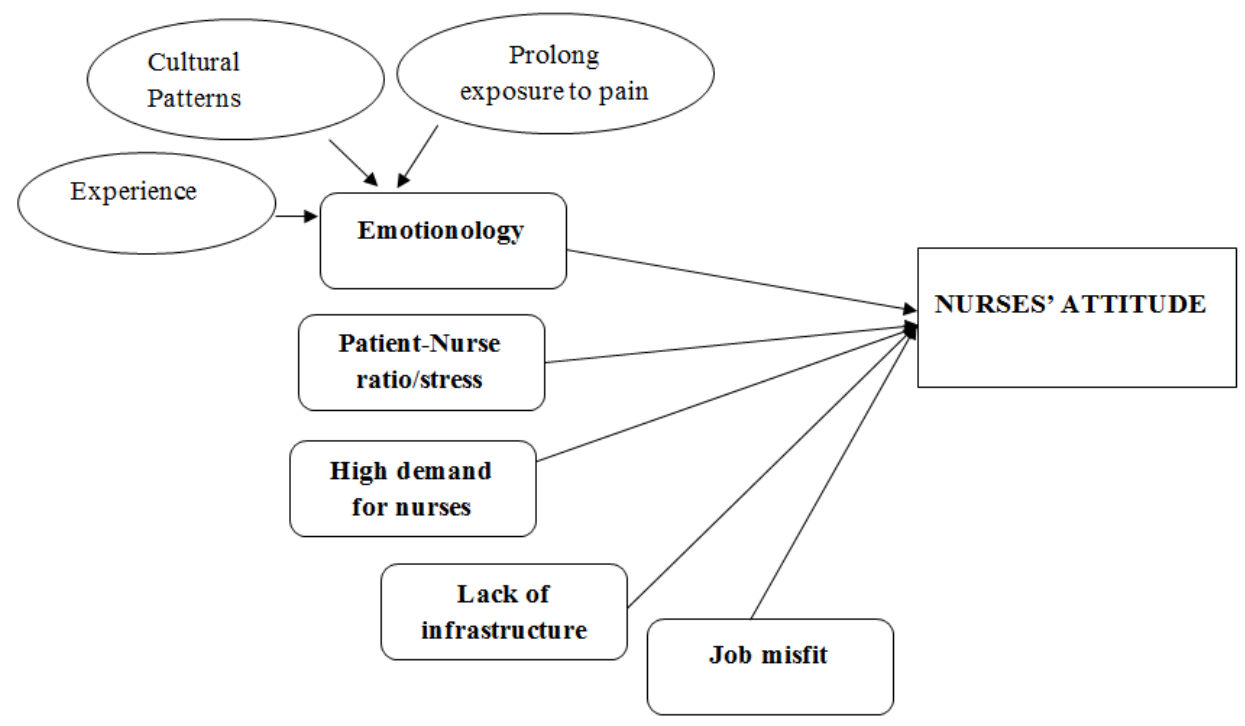

Figure 1. Antecedents of Nurses' Attitude

Thus, the identified factors that explain the poor attitude of the nurses include reaction to the ill-treatment or behavior from some patients, work-overload, inadequate infrastructure, prolong exposure to pain, lack of person-job-fit, high demand for nurses which make them feel indispensable, and some cultural beliefs which make the nurses feel that patients are reacting inappropriately (e.g. a man crying at the hospital would be seen as over reaction, and would receive harsh reaction from the nurses). The problems can be viewed as emanating from the individual nurses, as well as structural/organizational deficiencies. The model below summarizes the factors identified.

\section{Recommendations for Improving Nurses' Attitude}

\subsection{Individual and Organisational Centred (IOC) Model}

We provide an organisational development intervention aimed at improving the work attitude of nurses from the individual and organisational levels. The proposed interventions are based on the antecedents of the attitude of nurses identified above. The individual level mainly has to do with the emotionology aspect of the antecedents identified, whereas the organisational centred strategies have to do with policy framework and suggest organisational structure that promotes teamwork, and also utilise the available resources effectively. We believe that combining these interventions with the possible sanctions for nurses who would exhibit gross professional misconduct, would go a long way to improve the attitude of Ghanaian nurses.

One effective approach for changing attitudes is to employ a cognitive modifier to challenge the person's behavior by providing new information. It is important to note that attitude transformation takes time, effort, and determination, but it can be modified. Moore, cited in Nash (2011) emphasized the need for managers to understand that attitude change takes time and should not set unrealistic expectations for rapid change. 
Work attitude of Ghanaian nurses for quality health care service delivery: Application of IOC interventions

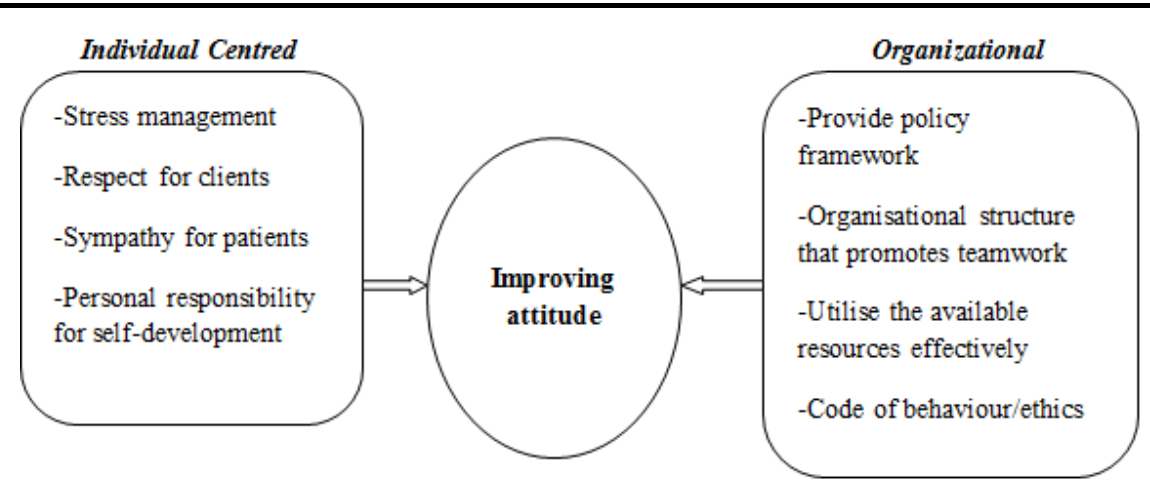

Figure 2. Individual and Organizational centred model for improving nurses' attitude

The model above depicts the Individual and Organisational Centred (IOC) model which indicates the suggested ways that the attitudes of the nurses could be improved to enhance health services delivery. It consists of individual centred interventions, and organisational centred interventions. Detailed descriptions of the intervention strategies are provided below.

\section{Individual Centered Interventions}

One of the key antecedents identified has to do with stress resulting from work overload. This particular issue could be dealt with from both individual and organizational levels. On the organizational level, the nurses could be taught stress management techniques to help them deal with the stressful situations they experience. There is also the need for the nurses to be trained to develop person skills to help them relate with their clients with respect. Patients often complain about the ways nurses in the public hospitals relate with them. Nurses could be made to give weekly report to their supervisors and any challenges they had would be addressed. Regular sessions could be held to help nurses acquire the necessary people skills and person management skills they need to act in a professional manner.

It is also essential to prime the state or condition of the patients, making nurses understand that their patients are sick and in pain. When this is made salient and the nurses are sensitized that the behavior of the patients could deviate from the norm and that they deserve some sympathy, it would go a long way to improve the nurse-patient relationship. Nurses could also be made to take personal responsibilities for the development of interpersonal skills to help them in their profession. This would boost their occupational self-efficacy and self-esteem. When this happens, they are less likely to denigrate their patients to psychologically boost their own self esteem. Getting people to focus on positive aspects of themselves (self-affirmation) reduces the need to denigrate others in order to get a self-esteem boost. Individuals always strive to maintain a positive image of themselves, perceiving themselves as desirable and favourable (Steele \& Liu, 1983). The nurses could rather be taught to engage in self-affirmation. This is a process in which individuals reflect upon their values and aspects of their lives they most value, and after they consider the facets of their life they most value, they are less inclined to exhibit anxious or defensive responses in the aftermath of criticisms, rejections, or other personal threats.

Self-affirmation has been found to diminish the effect of personal threats on attitudes towards other ethnicities, roles, and many others (Rudman, Dohn, \& Fairchild, 2007). It has also been found to have facilitated the capacity of people to disengage when necessary (Vohs, Park, \& Schmeichel, 2012), thereby saving personal resources for efficient performance. The conservation of resources theory postulates that personal resources such as perceived control, self-efficacy and perceptions of improvement enhance performance and reduces work stress, as well as promoting positive work experiences.

\section{Organizational Centered intervention}

At the organizational level, a number of interventions have been proposed. These are elaborated in the next 
section.

Screening assessment before admitting - We suggest that potential nurse trainees must be screened before admitting them onto the program to receive training as nurses. Individuals have diverse career self-view (Heslin, 2005) and when there is congruence between their career self-view and the demands of the job, they are more likely to evaluate their career positively and attain satisfaction in their work experience. Danziger and Valency (2006) proposed that individuals whose career anchors are congruent with their job report a significantly higher mean level of job satisfaction and are more involved in their job than those who lack such congruence. There is also the need for employees to possess the right competences, inner drives and values in other to have a satisfying work experience. The need for person-environment fit in a contemporary turbulent employment context was emphasized by Schreuder and Coetzee (2011). It seems that little or no attention is paid to internal aspect of individual's career which focuses on self-concept and career values.

Regular in-service/stress management training - Regular in-service and stress management training are suggested to help the nurses be up to date on their functions and discharge their duties professionally. In-service training would equip the nurses with the requisite competences required to deal with their job demands and boost their occupational self-efficacy. When employees have the right competency needed for a given job, they are likely to exhibit positive work attitude even in challenging time (Schreuder \& Coetzee, 2011; Van Viamen, 2018). The in-service training content could include stress management skills to help the nurses to deal with the job demands. An important personal resource that has been identified to help employee cope with demanding job circumstances is psychological flexibility. This represent an individual's ability to contact the present moment while embracing internal experiences without attempting to control them, and persist or change his or her behavior, depending upon what situations they find themselves (Hayes, Luoma, Bond, Masuda, \& Lillis, 2006).

Psychologically flexible individuals have been found to be less likely to exhaust resources such as energy and attention, and have more resources available to them to respond to job demands without becoming exhausted (Baer, 2003). Individuals could be trained to acquire this personal resource through the acceptance and commitment therapy (Hayes, Strosahl, \& Wilson, 1999) at the workplace as part of their in-service training. Psychologically flexible employees are expected to be able to cope better with emotional job demands because they are open and non-judgmentally aware of the emotional demands (Baer, 2003; Hayes et al., 2006).

Enforcement of policies and Code of behavior/ethics - A major setback observed at the public health facilities is the lack of enforcement of work policies. There are pragmatic codes of ethics and organizational policies that could make nurses work professionally and treat their patients with respect and care. The code of ethics for the Ghana Health Service stipulates general principles and rules of behavior for all health workers in Ghana. The absence of enforcement of these rules of behavior (Ofosu-Kwarteng, 2012) created an avenue for the nurses to do anything and go away with it, a situation that is largely or even entirely different at the private health facilities because of strict enforcement of rule and policies.

Utilize the available resources effectively - There is also the challenge of inadequate resources at the health facilities, which some nurses cite as a reason of their frustrations and eventual unfavorable attitude toward their patients. We propose that management takes steps to manage the limited resources at the health facilities, including the personnel or the human resources. Efficient schedules of personnel and allocation of resources would go a long way to help in managing the resources.

Organizational culture that promotes teamwork - Effective teamwork is very essential in contemporary work settings. Social resources such as emotional support, assistance from friends and family serve as buffer against the potential negative impact of stressful life events which conserves personal resources for the employee to function at his or her optimum level with positive feelings (Lazarus \& Folkman, 1984). Teamwork reduces stress and the feeling of belonging to a team boosts the morale of teammates. It also serves as a check on work attitude of the team members. 
Work attitude of Ghanaian nurses for quality health care service delivery: Application of IOC interventions

Best behavior award - We finally propose a system for identifying the best behave nurse in every unit and awarded publically to encourage such behavior. The ABC model of behavior modification (Daniels, 1999) suggests that the consequence that follows a given behavior is a crucial element in determining whether that behavior would be repeated. Much as there is the need to enforce policies and sanction unwelcome work attitude, it is equally or more important to acknowledge and recognize desired behaviors to encourage their recurrence.

\section{Summary and Conclusion}

The paper presents how the attitude of nurses in especially the public hospitals in Ghana is affecting quality health delivery in the country, and provides intervention strategies from organizational development perspective. The IOC model was used to provide individual and organizational centered interventions to improve the attitude of the nurses. The behavior of nurses in the health delivery system is very crucial as they are mostly those who interact with healthcare seekers. It is therefore very important for a healthy nurse-patient relationship to be promoted to facilitate health delivery. The proposed model is expected to enhance the quality of the relationship that exists between patients and nurses at the health centers in Ghana and elsewhere. This would lead to boosting of both nurses and patients' satisfaction with each other and the health delivery system in general.

\subsection{Practical Significance and Contribution}

This paper presents some challenges in the healthcare delivery system in Ghana with focus on the work attitudes of nurses, and offered interventions strategies to put in place to help improve healthcare delivery. The paper presented practical solutions to improve the work attitude of nurses, as they are critical personnel in the healthcare delivery system. The individual and organizational centered interventions provided in the paper have significant implications for improving healthcare delivery.

\section{References}

Ajzen, I., \& Fishbein, M. (1980). Understanding attitudes and predicting social behavior. Englewood Cliffs, NJ: Prentice-Hall.

Appiah, S. (2013). Health authorities to sanction nurses, midwives. Retrieved from http://www.graphiconline.com Asenso-Okyere, W. K., Osei-Akoto, I., Anum, A., \& Adukonu, A. (1999). The behaviour of health workers in an era of cost sharing: Ghana's drug cash and carry system, Tropical Medicine and International Health, 4(8), 586-593. https://doi.org/10.1046/j.1365-3156.1999.00438.x

Baer, R. A. (2003). Mindfulness training as a clinical intervention: A conceptual and empirical review. Clinical Psychology: Science and Practice, 10, 125-143. https://doi.org/10.1093/clipsy.bpg015

Baron, A. R., Branscombe, R. N., \& Byrne, D. (2009). Social psychology (12th ed.). Pearson Education.

Betsch, T., Plessner, H., \& Schallies, E. (2004). The value-account model of attitude formation. In G. R. Maio \& G. Haddock (Eds.), Contemporary perspectives on the psychology of attitudes (pp. 251-271). Hove: Psychology Press.

Booth, R. Z. (2002). The nursing shortage: A worldwide problem. Revisto Latino-Americano Enfermagem, 10(3), $392-400$. https://doi.org/10.1590/S0104-11692002000300013

Bruner, J. S. (1957). Going beyond the information given. In J. S. Bruner, E. Brunswik, L. Festinger, F. Heider, K. F. Muenzinger, C. E. Osgood, \& D. Rapaport (Eds.), Contemporary approaches to cognition (pp. 41-69). Cambridge, MA: Harvard University Press.

Daniels, A. (1999). Bringing out the best in people. New York: McGrawHill.

Danziger, N., \& Valency, R. (2006). Career anchors: Distribution and impact on job satisfaction: The Israeli case. Career Development International, 11(4), 293-303. https://doi.org/10.1108/13620430610672513

Dzomeku, V. M., Ba-Etilayoo, A., Perekuu, T., \& Mantey, R. E. (2013). In-patient satisfaction with nursing care: A case study at Kwame Nkrumah University of science and technology hospital. International Journal of Research in Medical and Health Sciences, 2(1). Retrieved from http://www.ijsk.org/ijrmhs.html

Edwards, W. (1954). The theory of decision making. Psychological Bulletin, 51, 380-417. https://doi.org/10.1037/h0053870 Fishbein, M., \& Ajzen, I. (1975). Belief, attitude, intention and behavior: An introduction to theory and research. Reading, 
Asamani, L., Agyemang, B. C., Afful, J., \& Asumeng, M.

MA: Addison-Wesley.

Ghana Health Service. (2011). Ghana health service 2011 annual report. Retrieved from https://www.ghanahealthservice.org/downloads/GHS\%202011\%20Annual\%20Report\%20Final\%2014-8-12.pdf

Ghana News Agency. (2009). Change negative attitudes- Nurses told. Retrieved from http://www.modernghana.com/news/231921/1/change-negative-attitude-nurses-told.html

Ghana News Agency. (2012). Nurses and midwives council expresses concern about poor client care. Retrieved from http://ghananewsagency.org/health/nurses-and-midwives-council-expresses-concern-about-poor-client-care-45292

Hayes, S. C., Luoma, J., Bond, F., Masuda, A., \& Lillis, J. (2006). Acceptance and commitment therapy: Model, processes, and outcomes. Behavior Research and Therapy, 44, 1-25. https://doi.org/10.1016/j.brat.2005.06.006

Hayes, S. C., Strosahl, K., \& Wilson, K. G. (1999). Acceptance and commitment therapy: An experiential approach to behavior change. New York: Guilford Press.

Heslin, P. A. (2005). Conceptualizing and evaluating career success, Journal of Organizational Behavior, 26, 113-136. https://doi.org/10.1002/job.270

Jones, L., Sinclair, R., \& Courneya, K. (2003). The effects of source credibility and message framing on exercise intentions, behaviours, and attitudes: An integration of the elaboration likelihood model and prospect theory. Journal of Applied Social Psychology, 33(1), 179-196. https://doi.org/10.1111/j.1559-1816.2003.tb02078.x

Lazarus, R. S., \& Folkman, S. (1984). Stress appraisal and coping. New York: Springer.

McGuire, W. J. (1968). Personality and attitude change: An information-processing theory. In A. G. Greenwald, T. C. Brock, \& T. M. Ostrom (Eds.), Psychological foundations of attitudes (pp. 171-196). New York: Academic Press. https://doi.org/10.1016/B978-1-4832-3071-9.50013-1

Nash, P. (2011). The effects of education and direct contact on explicit and implicit attitudes towards older people [Unpublished doctoral dissertation]. University of Glamorgan.

Ofosu-Kwarteng, J. (2012). Healthcare delivery and customer satisfaction in Ghana: A case study of the Koforidua regional hospital [Unpublished thesis]. Institute of Distance Learning, Kwame Nkrumah University of Science and Technology.

Rudman, L. A., Dohn, M. C., \& Fairchild, K. (2007). Implicit self-esteem compensation: Automatic threat defense. Journal of Personality and Social Psychology, 93(5), 798-813. https://doi.org/10.1037/0022-3514.93.5.798

Salia, A. K. (2007). Nurses attitude to patients deplored. Retrieved from http://askstories.blogspot.com/2007/11/nurses-attitude-to-patients-deplored.html

Schreuder, A. M. G., \& Coetzee, M. (2011). Careers an organizational perspective (4th ed.). Cape Town: Juta.

Shirimori A. (2001). Bad human relations of nurses affecting health delivery. Retrieved from http://www.Shirimori/Ghanadistrict.com

Stearns, P. N., \& Stearns, C. Z. (1985). Emotionology: Clarifying the history of emotions and emotional standards. The American Historical Review, 90(4), 813-836. https://doi.org/10.2307/1858841

Steele, C. M. (1988). The psychology of self-affirmation: Sustaining the integrity of the self. In L. Berkowitz (Ed.), Advances in experimental social psychology (Vol. 21, pp. 261-302). New York: Academic Press. https://doi.org/10.1016/S0065-2601(08)60229-4

Steele, C. M., \& Liu, T. J. (1983). Dissonance processes as self-affirmation. Journal of Personality and Social Psychology, 45, 5-19. https://doi.org/10.1037/0022-3514.45.1.5

Van Vianen, A. E. M. (2018). Person-environment fit: A review of its basic tenets. Annual Review of Organisational Psychology and Organisational Behaviour, 5, 75-101. https://doi.org/10.1146/annurev-orgpsych-032117-104702

Vohs, K. D., Park, J. K., \& Schmeichel, B. J. (2012). Self-affirmation can enable goal disengagement. Journal of Personality and Social Psychology, 104, 14-27. https://doi.org/10.1037/a0030478

Zajonc, R. B. (1968). Attitudinal effects of mere exposure. Journal of Personality and Social Psychology, 9 (Part 2, no. 2). https://doi.org/10.1037/h0025848

Zborowski, M. (1952, 2010). Cultural components in response to pain. Journal of Social Issues, 8, 16-30. https://doi.org/10.1111/j.1540-4560.1952.tb01860.x 